\title{
CHANGE OF CONTRACTOR'S STATUS IN THE SYSTEM OF NATIONAL ACCOUNTS
}

It is assumed that methodological foundation of national accounting is based on the principles of political economy, accounting and statistics. However, the author of the present paper believes that market turnover reproduction processes, as well as interaction of the given processes, were not sufficiently covered in periodicals dedicated to the SNA problems. Thus, the timeliness of the paper is associated with an attempt to show that the substance of the fundamental law of self-preservation in the context of unbalanced estimates regarding modern 
reproduction and real market turnover appears either as conservatism trends, or development trends in the market economy. The aim of the present paper is to determine specifics of dual substance of counterparties in the national economy, which establishes their status as producers and consumers. Problem analysis referred to reproduction regularity formalization, an effect of such regularities on market turnover, as well as building a logical scheme and subordination of reproduction categories, make it possible to achieve the goal and identify a study algorithm regarding counterparty status change. The author of the paper applies methods of "pure economy" - mathematical methods, in particular, as well as methods of political economy, including a dialectics method. The results obtained in terms of new knowledge on interaction of reproduction processes and market turnover make it possible to determine current trends in the economic system. Moreover, description of a generic term, material basis, form of function and systemdefined quality helps estimating a degree of dominant feature combination, determine counterparties' ability to develop or preserve various production activities, and, finally, stimulate ability to change status of counterparties. The main conclusion of the present paper is that the SNA can be treated as an "ex-ante" analysis within the suggested approach, rather than an "ex-post" analysis suggested by traditional "Economics". And such treatment meets the requirements of the new economy, i.e. economy of knowledge, based on predictive modeling of economic processes.

The introduction to the book "Problems and Contradictions of Reproduction in Russia in the Context of Global Economic Development. Theory. Comparison. Research" edited by V. N. Chernovets points out that all the processes in the context of production and consumption may be generated only under the conditions of market-capitalist reproduction characterized by "standard" contradictions, continual resolution of which leads to economic development [6]. However, as a result of the widespread neoclassic concepts of "homo economicus" and "methodological individualism", the ideas of reproduction have not become predominant for economic analysis and assessment of economic activity. At present, basic characteristics of economic activity are commercial and economic turnover that assums such exchange transactions, under which incomes of some parties appear as expenses of other parties, and vice versa.

Sampling analysis of over 750 Russian periodicals dedicated to the SNA problems demonstrated the fact that about 200 articles are devoted to the basic subjects, such as theory and methodology, balance and disbalance, business cycle, interpretation of production functions, mathematic and statistic methods, sustainability of development, prediction and optimization, national wealth, financial aspects, principles of structuring, logic, analysis and assessment of the national accounts. However, as for the most important research field, namely, integrated assessment of reproduction processes in the SNA, there are very few publications of this kind [1, for instance]. Therefore, modern economic periodicals introduce and apply extensively the concepts of expanded economic activity, equitable participation of production factors in creation of an added value, formation of the GNI for account of business activity of non-residents, and harmonization of estimated figures in the existing reporting forms in accordance with the requirements of supranational institutions. Table demonstrates that the periodicals representing different scientific approaches make attempts to find in the SNA methodology answers to the questions of high interest for the readers.

The above-mentioned periodicals support the uniform approach to the SNA problems. But more important is the fact that in case of such SNA interpretation the substance of the fundamental law of self-preservation is manifested more through conservatism trends, rather than development trends.

It is a well-known fact that discernment of the law of self-preservation in the economic theory is accomplished through analysis of reproduction as the objective of existence of any economic system. Practical experience shows that efficiency of any economic system under continual motion and modification of reproduction is specified mainly by a life cycle of created utilities. The value of the cycle changes principally due to development of scientific and research ideas, as well as due to marketing that secures progress in production of goods and services, as well as their modernization.

The majority of papers consider reproduction ability as a peculiar circulation, within which all producers in the effort to gain profit offer various goods and services creating thus consumers' solvent demand. As a result of bidding, producers and customers begin to find out, which goods and services and under what conditions are better to sell and buy, and how to find balance in reaching prosperity. Such external manifestation of circulation covers an underlying essence of reproduction, according to which utilities and services intended for meeting certain demands objectively link producers with their counterparties, who buy the given utilities and services to accomplish self-actualization and create their own utilities and services for further supply on the market. 
Rate of publications in Russian periodicals dedicated to the SNA

\begin{tabular}{|c|c|c|}
\hline Title of Periodical & $\begin{array}{c}\text { Number of } \\
\text { Publications }\end{array}$ & $\begin{array}{l}\text { Publica- } \\
\text { tions, \% }\end{array}$ \\
\hline Statistics issues & 80 & 41,9 \\
\hline Region: Economy and Sociology & 15 & 7,9 \\
\hline Economist & 9 & 4,7 \\
\hline Russian Economic Magazine & 9 & 4,7 \\
\hline Prediction issues & 7 & 3,7 \\
\hline Equity Market & 7 & 3,7 \\
\hline Federalism & 6 & 3,1 \\
\hline Higher School Of Economics & 6 & 3,1 \\
\hline Finances and Credit & 5 & 2,6 \\
\hline Accounting & 4 & 2,1 \\
\hline Questions of Economy & 4 & 2,1 \\
\hline $\begin{array}{l}\text { Problems of Management, } \\
\text { Theory and Practice }\end{array}$ & 3 & 1,6 \\
\hline $\begin{array}{l}\text { Russian Economy: Predictions } \\
\text { and Trends }\end{array}$ & 3 & 1,6 \\
\hline Belarus State University bulletin & 3 & 1,6 \\
\hline $\begin{array}{l}\text { ECO. Economics and } \\
\text { Management in Industrial } \\
\text { Production }\end{array}$ & 3 & 1,6 \\
\hline Nature Management Economics & 2 & 1,0 \\
\hline $\begin{array}{l}\text { BOSS: Business, Organization, } \\
\text { Strategy, Systems }\end{array}$ & 2 & 1,0 \\
\hline $\begin{array}{l}\text { Information Bulletin of the Ural } \\
\text { State University of Economics }\end{array}$ & 2 & 1,0 \\
\hline Resources of Russian Regions & 2 & 1,0 \\
\hline Finances & 2 & 1,0 \\
\hline Oil of Russia Magazine & 2 & 1,0 \\
\hline \begin{tabular}{|l} 
Economy of Agrarian and \\
Reprocessing Enterprises
\end{tabular} & 2 & 1,0 \\
\hline Chief Accountant & 1 & 0,5 \\
\hline $\begin{array}{l}\text { Economic Analysis: Theory and } \\
\text { Practice }\end{array}$ & 1 & 0,5 \\
\hline $\begin{array}{l}\text { Financial and Accounting } \\
\text { Consulting }\end{array}$ & 1 & 0,5 \\
\hline $\begin{array}{l}\text { Library of the Novosibirsk } \\
\text { Region: State-Financed } \\
\text { Enterprises }\end{array}$ & 1 & 0,5 \\
\hline Money and Credit & 1 & 0,5 \\
\hline $\begin{array}{l}\text { Statistics: Stock Indices, } \\
\text { Macrodinamic Criteria, Security } \\
\text { Quotations }\end{array}$ & 1 & 0,5 \\
\hline $\begin{array}{l}\text { Construction Materials, } \\
\text { Equipment, Technical Policy in } \\
\text { the } 21^{\text {st }} \text { Century }\end{array}$ & 1 & 0,5 \\
\hline ECOS-Inform & 1 & 0,5 \\
\hline $\begin{array}{l}\text { Economic and Mathematical } \\
\text { Methods }\end{array}$ & 1 & 0,5 \\
\hline Observe & 1 & 0,5 \\
\hline $\begin{array}{l}\text { Intellectual Liberty in the } 21^{\text {st }} \\
\text { Century }\end{array}$ & 1 & 0,5 \\
\hline Innovations in the $21^{\text {st }}$ Century & 1 & 0,5 \\
\hline Finances, Money, Investment & 1 & 0,5 \\
\hline
\end{tabular}

Application of the methods and terminology of "pure economy" makes it possible to formalize the most significant processes of reproduction and determine their role in market turnover.

Let us introduce the following parameters:

$R p$ - reproduction potential (rate of economic activity);

$\sum A-$ sum total of transaction and speculative operations (work);

$t$ - time ( $\Sigma-$ totality of periods);

$T-$ period (time of one cycle);

$P f-$ efficiency of production factors (efforts);

Mlc - scale of "life cycle";

$n-$ number of cycles.

Then the functional dependence of reproduction and economic turnover will be:

$$
\begin{aligned}
& R_{p}=\frac{\sum A}{t}=\frac{P f \cdot M l c}{t}=\frac{P f \cdot M l c}{T}= \\
= & \frac{P f \cdot M l c}{t / n}=\frac{P f \cdot M l c \cdot n}{t}=\frac{P f \cdot M l c}{t} \cdot n .
\end{aligned}
$$

Hence,

$$
n=\frac{R_{p} \cdot t}{P f \cdot M l c} .
$$

Formula (2) means that turnover in any market economy is directly proportional to reproduction potential and time (part of the whole period) and inversely related to efficiency of production factors (efforts) and a life cycle scale. In other words, the higher the values of reproduction potential are, to a greater extent reproduction gravitates towards development.

If formula (2) is transformed as follows:

$$
n=R_{p} \cdot K,
$$

then economic turnover is predetermined by reproduction, and it is corrected by the coefficient, which shows the ratio between time (totality of periods) and the life cycle scale.

Formalization of reproduction and economic turnover processes implies analysis of their political and economic nature, the core of which is transactions between counterparties.

Dual nature of counterparties' essence in every following period appears in the fact that each of them is both a producer and a consumer at the same time. Therefore, reproduction is specified not by an abstract preference and desire to buy certain wealth, but desire of consumers to find on the market only such products, which will create conditions for their self-actualization in the process of production of new goods and services that differ from those offered on the market. 
To build a logic scheme and subordinate the categories (terminology) of reproduction, let us apply an approach suggested by Prof. E. P. Dyatel [2], used for drawing up of a short and structured summary on economics of an enterprise. He wrote this paper as an answer to the works by German professors F. K. Bea, E. Richtel, M. Schweitzer [7] (Fig.).

\begin{tabular}{|c|c|c|c|}
\hline Generic feature & $\begin{array}{c}\text { Material } \\
\text { basis } \\
\text { (substance) }\end{array}$ & $\begin{array}{c}\text { Form of } \\
\text { functioning }\end{array}$ & $\begin{array}{c}\text { System- } \\
\text { defined } \\
\text { quality }\end{array}$ \\
\hline
\end{tabular}

Fig. Subordination of the system of categories (terminology)

The concept of reproduction is interpreted by the German researchers as "supply with investment goods..., which takes part in numerous recurrent production cycles as a bench mark of a production process". Such an approach allows E. P. Dyatel, the author of the thesaurus, defining the mentioned postulate as a generic feature of reproduction, namely, as "supply with investment goods as a specific field of production" [2].

However, a more valid approach to systematization of knowledge related to reproduction assumes not only description of its generic features, but also the generic term, which incorporates a diversity of integral features, including "supply with investment goods".

Coherence between demand, goods (services) and resources the given goods and services are produced from, makes it possible to determine essential factors of reproduction in their interaction. The first factor signifies increasing demand that results in unrestrained growth of new ne utilities multiplying in the minds of counterparties due to high-pressure advertizing. The second factor is determined by the way counterparties' growing demand is satisfied and specified by their economic opportunities. Moreover, the source of development of the mentioned opportunities at nano- and microlevels of production are determined, first, by capability of the counterparties to produce utilities from the acquired resources at a specified rate of added value. Second, economic opportunities of counterparties are determined by a property size with specific income from the ownership and disposal. At the level of economic structure aggregation, i. e, in the process of macroeconomic research, economic opportunities of counterparties are determined by the GNP and GNI values, which in turn depend on production factor balance.

Thus, determination of the generic term for reproduction is based on the results of an economic structural analysis, transformation of the economic structure and changes under combination of essential factors such as demand of counterparties and their economic opportunities. Commonness of combination factors implies absolute coherence of production and consumption, which signifies balance and perfect status of counterparties.

An incompatible area referred to the "counterparties' demand" factor as applied to the "economic opportunities" factor signifies imbalance of production and consumption, which gives rise to development of economic opportunities in terms of creation of new utilities; incompatible areas between the "economic opportunities" factor and the "demand" factor are also characterized by imbalance, and they may stimulate marketing, or layoff.

Thus, the generic term of reproduction is transformation of counterparties' economic status. Life cycle evolution of such counterparties occurs as a result of appropriation of disposable income not for any purchases, but only for those acting as resourses (factors of production) for creation of utilities with a specified added value at every consequent period of production and consumption. In reality the given generic term is considered as goodwill i.e. reliable reputation of counterparties.

Another element of reproduction knowledge systematization is specified by a material basis (substance). The German researchers define the given basis as investment, i.e. "capital expenditures intended for enterprise service..., for compensation of consumed resources, as well as rationalization and enhancement of the existing means of production ... Moreover .... release of invested capital... allows determining them as... disinvestment [7].

The suggested approach to definition of the material basis for reproduction interferes with coherence of investments as a substance of reproduction and the generic term of reproduction. The matter is that capital transactions of counterparties are a necessary but inadequate condition for counterparties' development. It means that by producing utilities they may either create a "leverage" for the counterparties or increase their debt loads in the context of the existing investments.

Thus, the material basis (substance) of reproduction is not only quality and amount of capital (investment) inputs, but capability of counterparties for self-development or conservation of various types of activities.

It is no accident that while systematizing the term "reproduction", the German researchers determined one of its forms as "financing ... i. e.... different activities connected with purchasing and return of funds, as well as execution of the corresponding payment documents, monitoring and insurance" [7].

Indeed, barter form of exchange is not typical for modern production. On the contrary, a money form 
acquires higher priority due to expansion and variety of a utility structure and an added value of these utilities. Money may signify different demands in the process of transformation of counterparties' status. However, the main purpose of money for reproduction material basis description is supply of counterparties with necessary financial recourses, as the main property of money or money equivalents is to provide exchangeability of different utilities. In other words, monetary aggregates and their production instruments express specific needs in the process of their transfer from one counterparty to another. Therefore, the major purpose of financing under specific type of reproduction is to deliver the required monetary resources to counterparties, who use the given resources for capital transactions with an objective to create new utilities as a reaction to new consumer demand. It is no accident that the subject of the modern economic research is quantity of money and an attempt to answer the question: what amount of money should circulate in the system of counterparties?

The answer is quite evident: counterparties need money to satisfy their needs in resources (factors of production) required for further cycles of reproduction. But then there is another question: what cost of created utilities will satisfy counterparties? Franzois Quesnay was the first who tried to answer a similar question: "Fundamental cost of goods depends on expenditures or costs necessary for production... An agricultural nation should seek to sell products at the highest possible level of prices and preserve the given level, since high prices stimulate development of the nation, and the result is maximal prosperity" [4].

The above-mentioned factors specify the fact that any price is a kind of investment in economic growth, welfare and, consequently, in transformation of counterparties' status. However, such superficial understanding of price covers "the bottom part of the iceberg", which is referred to as a total number of transactions, giving an idea about an amount of money required for counterparties. First, every element of technology of certain utilities by a counterparty includes a specific quantity of proper resources that should be purchased during each of the following cycles. Such dependence can be observed in cost balance of any counterparty, and average unit cost can be determined on the basis of the given cost balance. Second, transformation of counterparties' status depends on output growth rate. Therefore, if average unit costs are integrated with an output growth rate, it will be possible to determine the cost of goods (services). However, a time lag of price-setting means generation of ex ante costs (i.e. future or planned costs) and a corresponding ex ante growth rate.
Each counterparty considers the process of circulation of resources, goods and money only as a process of money circulation, i.e. a process of profit-making. However, price setting is not so much an individual activity of each counterparty, but rather a result of interaction in the system of counterparties. It is possible to say that the result of activity of a particular counterparty is observed in an ability to satisfy other people's needs. The given result is more evident in output growth rates, rather than in profit margin. It is no coincidence that Franzois Quesnay realized connection between cost and further reproduction based on linking a producer's income to the following production growth, i.e. creation of new utilities to the growth rates.

The formula of price set by counterparty includes a complex of functional components, for instance, growth of demand of a consumer-counterparty, ex ante growth rates and ex ante unit costs borne by pseudoproducers (intermediaries), as well as technological coefficients of a producer-counterparty. Therefore, it is totally incorrect to state that price of a producer-counterparty depends on the growth rate, which the producer-counterparty has selected a priori. A rational and efficient counterpartyproducer complies with the specified reproduction ratios, and, consequently, growth rates of counterparty's business are determined objectively by the whole system of counterparties operating in the correspondent market economy.

Thus, a counterparty-producer determines only production technology specified by the mentioned party's technological coefficients. Then price-setting is influenced by technological coefficients of counterparty-consumers, which gives ground to assert that price-setting of counterparties depends on the whole system of their technological coefficients. Moreover, it might be supposed that price of every utility is a derivative of the proportions specified by the market economy technology. In this connection, it is advisable to extend the form of functioning of reproduction material basis suggested by the German researchers with such elements of the financial instruments, which are adopted by the SNA93 international standard and an updated edition of 2008-2009. The matter deals with specification of operations connected with transfer of financial asset ownership, including creation and liquidation of financial claims as well as harmonization of a balancing item of capital transactions account (an investment result) and a balancing item of a financial account. This allows objectively evaluating status of any counterparty in the process of its reproduction.

Finally, the description originated from interaction of the generic term, substance and pattern 
of reproduction makes it determined by its system quality in the process of the reproduction knowledge systematization. The German researchers determined the mentioned concept as an approach aimed at identification and solution of problems connected with enterprise staff irrespectively of the functional field the given problems are solved in [7]. Modern economists note that "attraction force of additional capital and labor inflow necessary for reproduction of a certain kind of activity depends on capital productivity expressed in an added value. Therefore, commodity market operation requires two opposing economic forces associated with the given product (utility)" [4]. And in case we speak about opposing forces, there is no point in being afraid to use such features, which most correspond to these processes, for instance, the term "transformation of counterparties' status". The more so is that the core of a goal-oriented economic activity is in timely identification of problem situations and trends in the status of economic agents and in development of effects that will either preserve the required status or ensure necessary changes. Besides, imbalance in status and trends of an economic activity may often pose a threat [4]. That is why from the point of view of reproduction, system quality is undoubtedly a staff problem irrespective of a functional field of its origin and solutions, as shown by the German scientists.

In our opinion, the most adequate characteristics of interaction between the generic term, substance and pattern of reproduction is such a system quality, which secures status of counterparties capable either to develop the economic system or conserve it. Experience in terms of spontaneous organization of counterparties' client networks aimed at placement of deposits in the context of the current crisis, or well-developed multi-level marketing (MLM) client networks and other dealer networks vividly demonstrate ambiguousness of counterparties' status transformation at the present stage of the world development and the influence of the mentioned status on the economic system change.

\section{References}

1. Belolypezky, V. G. (2006). Business Constant in Reproduction of Economic Systems. Moscow State University Bulletin, vol. 6. Economics, 3, pp. 3-15.

2. Dyatel, E. P. (2000). Enterprise Economics. Thesaurus. Ural State University, $190 \mathrm{p}$.

3. Ivliev, I. V. (2007). Registered Program for ECM, Data Base "Forcing-Module of Macroparts in Economic Reproduction Process”, September 20, №2007614028

4. Kardash, V. A. (2006). Conflicts and Compromises in Market Economy. Science (Nauka), 248 p.

5. Quesnay, F. (1960). Selected economic works. SocioEconomic Literature Publishing House.

6. Problems and Contradictions of Reproduction in Russia in the Context of Global Economic Development. Theory. Comparison. Research. TEIS. 2004. 459 p.

7. Economy of an enterprise. INFRA-M. 1999. 928 p.

\section{U.D.C. 330.534(470)}

Keywords: system of national accounts (SNA), reproduction: generic term, material basis (contents), form of activity, systemdefined quality 